\title{
Carer perception of palliative care service at Provincial General Hospital, Ratnapura
}

Ramadasa G $\mathbf{U}^{1}$, Pathirana $\mathbf{K}^{1}$, Karunathilake $\mathbf{R}^{1}$, Perera $M \mathbf{C}^{1}$, Siriwardhana $\mathbf{L}^{1}$, Jayasekera $\mathbf{C} \mathbf{J}^{1}$, Thaibudeen M A ${ }^{1}$, Ranaweera S P A L ${ }^{1}$, De Silva R E E

Journal of the Ceylon College of Physicians, 2016, 47, 76-81

DOI: http://doi.org/10.4038/jccp.v47i2.7787

\begin{abstract}
Introduction: Palliative care improves quality of care for patients with life threatening illnesses and their families. It is common for families and, less often, friends to willingly take on the role of informal carer, even though this is often at considerable psychological, physical, social, and financial cost to themselves.
\end{abstract}

Objectives: To describe carer perception towards the Palliative Care Service in Provincial General Hospital, Ratnapura.

Methods: Palliative care services were provided at the Hospital for 172 patients from June 2014 to August 2016. We conducted a qualitative study to understand carer perceptions towards this new service. Semi-structured telephone interviews were conducted using qualitative research methods among 22 carers of patients who have obtained this service for over 3 months. These interviews were conducted with the aid of a preformed interviewer guide based on themes, satisfaction towards palliative care services, benefits received through the service and difficulties faced in caring for the ill person. All interviews were transcribed and analysed qualitatively using open explorative thematic coding.

Results: Mean age of the carers was 44.9 years (SD 11.1), 63.6\% ( $n=14)$ were females, majority $(50 \%)$ were educated up to O/L, duration of care giving in the majority (50\%) was 6-12 months,

\footnotetext{
${ }^{1}$ Provincial General Hospital, Ratnapura.

${ }^{2}$ Family Medicine Unit, Faculty of Medicine, University of Colombo.

Corresponding author: GUR

E-mail: uramadasa@yahoo.co.uk
}

majority of the care givers were a child of the patient (50\%). Mean age of patients was 63 years (SD 11), majority had malignancies (68.1\%, $\mathrm{n}=15$ ), and approximately half had 1-2 comorbidities.

Majority stated that the palliative care service listened to and understood the needs of the patients, that adequate information and education was provided. "Opportunity was provided to share our views and worries, and talk about our roles as carers, and support was provided". Majority were highly satisfied with the service. Benefits obtained through the service were, patients could be cared for in their own homes with family members, and patients had comfortable and peaceful death. Special advice and guidance provided was beneficial to improve the physical and psychological state of patients and carers, such as pain relief, improved sleep, appetite and feeding. Carers were able to understand the disease prognosis and pre-plan to fulfil patient expectations. Some patients also received assistive devices through the service which greatly benefitted them. The service was also able to avoid frequent hospital admissions, arrange hospice care when needed, and arranged financial assistance.

Difficulties faced in caring for the patient included loss of job and occupation, financial difficulties, hardships in transporting patients from home to hospital, having to travel long distances, poor support from some family members in caring for the patient which increased carer burden, and children's schooling and education being adversely affected.

Conclusions: The majority of carers were satisfied with the service provided and perceived benefit from the Palliative Care Service provided by Provincial General Hospital, Ratnapura.

Key words: carer satisfaction, palliative care, caregivers, quality of life 


\section{Introduction}

Palliative care was founded on a holistic philosophy encompassing the physical, psychosocial and spiritual needs of patients with life limiting illnesses and those of their families. ${ }^{1}$ The terminally ill patients die due to chronic disabling diseases with a related huge symptom burden. It is reported that cancer patients spend about $90 \%$ of the last year of life at home. ${ }^{2,3}$ This has benefits for the patients and the health care systems. However the burden and rewards of caring for people in their last year of life are shared between informal carers who are usually relatives and friends or neighbours and healthcare professionals working in institutions or in the community. The National Institute for Health and Clinical Excellence UK (NICE) defines family carers as people with a close social and emotional bond, not just those related by kinship or marriage. ${ }^{4}$ It is known that one of the main benefits of being in the home setting is the ability to continue with normal life as long as possible. ${ }^{5}$

One of the core concepts of palliative care is improving quality of life of patients and their families who are facing life limiting illnesses. In a qualitative study carried out in the UK, patients and carers emphasised the importance of good anticipatory care, particularly provision of information and advice to patients and carers $^{6}$. It is also reported that carers of palliative care patients face particular stress, and this has led to an increase in patient admissions. ${ }^{2,7}$ Another study reported that the specific expectations from the perspective of patients and carers are professionalism, expertise and facilitation. ${ }^{8}$ A study carried out in Sri Lanka reported that, cancer patients in Anuradhapura have no problem of accepting their diagnosis of cancer and its complications contrary to the wishes of their close relatives and some doctors. ${ }^{9}$

It is known that good holistic care helps family carers to maintain a normal life by reducing the burden of care. ${ }^{10}$ The Palliative Care Service of the Provincial General Hospital, Ratnapura is committed to provide a support system to patients and their carers.

\section{The journey of palliative care in establishing the Palliative Care Service}

The interest in palliative care in Sri Lanka was generated by the National Cancer Control program and the Ministry of Health in 2012 and Ratnapura was identified as a suitable place for a pilot project in palliative care. Several meetings were held with stakeholders from PGH Ratnapura and the National Cancer Control Program. A formal palliative care service with multidisciplinary team was commenced in 2014. Our multidisciplinary team includes a palliative care physician, the treating physician from where the referral had originated, one medical officer, palliative care nurse, physiotherapist, speech therapist, social workers who were trained for counselling as well, pharmacist, occupational therapist and a nutritionist. Palliative care services were provided for 173 patients from June 2014 to August 2016 at the hospital. One hundred and five (105) of them were patients with cancer. We maintained telephone contact with patients and families. In spite of the usual clinic day being Tuesday, patients were welcomed on any working day depending on the need. We conducted meetings with patients and families to explain about the disease condition and the expected outcome, to set up goals of care, for physical symptom control such as pain, improve quality of life, special needs in caring at home, needs of carers, social, and spiritual aspects of care, to plan terminal care and home deaths, to discuss some interventions such as percutaneous endoscopic gastrostomy (PEG) or jejunostomy feeding tube insertion, pulmonary rehabilitation, and social needs. An understanding of the experiences and needs of these patients and carers is important in improving the care for these patients.

Therefore we carried out a qualitative study with the aim of obtaining an overview of how carers view this new service and to identify ways of improving our service.

\section{Methods}

We carried out a qualitative study to understand carer perceptions towards the palliative care service and 22 semi-structured telephone interviews were conducted with carers of patients who have obtained the service. Carers of patients who attended the palliative care service for over 3 months were included. A qualitative research sampling technique was used ${ }^{11}$; the carers were contacted over the phone, and telephone interviews were conducted until no new information was forthcoming ${ }^{11}$.

The interviews were conducted with the aid of a preformed interviewer guide based on themes regarding satisfaction towards the palliative care service, the benefits received through the service and difficulties faced in caring for the ill person. Some of the interviews were conducted after the death of their patients/ relatives. All interviews were transcribed and analysed qualitatively using open explorative thematic coding.

\section{Results}

Mean age of the carers was 44.9 years (SD 11.1 Yrs), 63.6\% ( $n=14)$ were females, majority (50\%) were educated up to $\mathrm{O} / \mathrm{L}$, duration of care giving in the majority (50\%) was 6-12 months, majority of the care givers were children (50\%). Mean age of patients was 63 years (SD $11 \mathrm{Yrs})$, majority had malignancies $(68.1 \%, \mathrm{n}=15)$, and approximately half the population had 1-2 comorbidities. 
Majority stated that the Palliative Care Service listened to and understood the needs of the patients, and that adequate information and education was provided. "Opportunity was provided to share our views and worries, and talk about our roles as carers, and support was provided". Majority were highly satisfied with the Service. Benefits obtained through the Service were, patients could be cared for in their own homes with family members, and patients had comfortable and peaceful deaths. Special advice and guidance provided was beneficial to improve the physical and psychological state of patients and carers, Eg: pain relief, improved sleep, appetite and feeding. Carers were able to understand the disease prognosis and pre-plan to fulfil patient expectations. Some patients also received assistive devices through the Service which greatly benefitted the patients. The Service was also able to avoid frequent hospital admissions, arrange hospice care when needed, and arranged financial assistance through Samurdhi.

Difficulties faced in caring for the patient included loss of job and occupation, financial difficulties, hardships faced in transporting patients from home to hospital, sometimes having to travel long distances, poor support from some family members in caring for the patient which increased carer burden, and childrens' schooling and education being adversely affected.

Table 1. Sociodemographic characteristics of carers and patients

\begin{tabular}{|c|c|c|}
\hline \multicolumn{2}{|c|}{ Mean age of the carers } & 44.9 years (SD $11.1 \mathrm{Yrs})$ \\
\hline \multicolumn{3}{|c|}{ Carer gender distribution } \\
\hline- & Male & $08(36.4 \%)$ \\
\hline- & Female & $14(63.6 \%)$ \\
\hline \multicolumn{3}{|c|}{ Carer levels of education } \\
\hline- & Up to Gr 5 & 7 (31.8\%) \\
\hline- & Up to $\mathrm{O} / \mathrm{L}$ & $11 \quad(50 \%)$ \\
\hline- & Up to $A / L$ & $3(13.6 \%)$ \\
\hline- & Graduate and above & $1 \quad(4.5 \%)$ \\
\hline \multicolumn{3}{|c|}{ Duration of care giving } \\
\hline- & $<6$ months & $8(36.3 \%)$ \\
\hline- & $6-12$ months & $11 \quad(50 \%)$ \\
\hline- & $>1$ year & $3(13.6 \%)$ \\
\hline \multicolumn{3}{|c|}{ Carers relationship to the patient } \\
\hline- & Children & $11 \quad(50 \%)$ \\
\hline- & Spouse & $6(27.2 \%)$ \\
\hline- & Relative & $5(22.7 \%)$ \\
\hline Mean ag & f patients & 63 years (SD 11 Yrs) \\
\hline Patients' & ain diagnosis - malignancies & $15(68.1 \%)$ \\
\hline \multicolumn{3}{|c|}{ Patients' comorbidities } \\
\hline- & None & $10(45.4 \%)$ \\
\hline- & One & $6(27.2 \%)$ \\
\hline- & Two & $5(22.7 \%)$ \\
\hline- & Four & $1 \quad(4.5 \%)$ \\
\hline
\end{tabular}


Table 2. Benefits obtained through the service

\section{Benefits stated by the carers}

The carers stated that the patients could be cared for at home, they went on to state that the patients were able to spend their end stage of the lives with the family members. They also emphasized the importance of providing tender, love and care to their loved ones. They also felt that the family bonds and understanding improved. (Patients 4,22)

Advice and guidance received from the palliative care team greatly helped us to care for the unconscious patients, and that this helped improve the quality of care during their end stages of life.

"Advice, treatment and social support was very helpful." ( 3 patients - 14,16)

"We were able to prevent bed sores with the advice; (Patients 8 and 11) Patient also received a comfortable air mattress". ( Patient 11)

Majority of the carers stated that patients' pain was relieved, and that they were able to sleep comfortably.

(Patients 2,3,15, and 18)

"Patients were mentally / psychologically satisfied." (Patients 1,2,3,11,15,19). Patients physical and mental status improved.

"Swallowing improved with simple postural modification",

"We could feed him with PEG tube".

"He could communicate with us through paper and pen".

"Wheel chair provided by the palliative care team immensely helped the patient",

"Air mattress provided by the palliative care team prevented bed sores".

"Breathing difficulty greatly improved with the oxygen mask and cylinder provided" - Patient with extrinsic allergic alveolitis.

"Financial assistance from the government, Samurdhi was provided".

"Reduced the frequency of hospitalization" (Patients 21,22), "Hospice care was arranged" (Patient 23).

Palliative care was available to talk anytime, this also helped to reduce expenditure.

"Patient received maximum care and was well satisfied",

"Peaceful death" (Patients 11,14,15,16)

\section{Table 3. Difficulties faced in caring for the patient}

\section{Difficulties faced}

Financial difficulties:

"Lost income and became dependant for daily expenditure", "Patient lost his job", Family member, sole bread winner lost his job'.

Transport difficulties:

"Had to face difficulties in transporting our bed ridden patient to hospital, "High cost of transport from home to hospital", "Had to travel a long distance to GH Badulla for radiotherapy".

Carers could not go to work on time. Some days the carers had to take leave to look after their relatives.

Less support from siblings:

In some families only one carer was available to look after the patient. "Only I was there to look after my elder brother. (Patient 8- was 57 years, had SAH, ICH and brain stem haemorrhage).

During periods of hospital stay finding a bystander was difficult.

Childrens' education/ schooling was badly affected. "Could not help children in their school work".

Family problems:

"Patients wife left home"

Another carer had an accidental burn, therefore had to look after 2 patients. 
Table 4. Questionnaire guide used for telephone interviews

1. Did you feel that Specialist Palliative Care Team listened to and understood the needs of the person you cared for?

All stated yes

2. What were the benefits that you feel that the person you cared for received ? (Table 2)

3. What are the difficulties that you and your family faced in caring for the ill person ? (Table 3)

4. Did you feel that the Specialist Palliative Care Team gave you the opportunity to share your views or worries about the person you cared for?

All stated yes

5. Did you feel you were given the opportunity to talk about your role as a carer and its effect on you ?

All stated yes

6. Did you feel the Specialist Palliative Care Team gave you support ? All stated yes, some stated very supportive

7. Did you feel the Specialist Palliative Care Team gave you enough information and education to help you care for the person you cared for?

All stated yes

8. Are you satisfied with the service you have received?

All stated yes

\section{Discussion}

\section{Summary of findings and comparison with the literature}

In this study we mainly focused on the needs of the family care giver and whether these facts have been addressed and whether the caregivers were satisfied with this new approach of holistic care given through our Palliative Care Service which is new to Sri Lanka.

There are some reported unmet needs among care givers, including information about the diagnosis and the expected outcome of the disease..$^{12}$ We have discussed these issues and carers were well satisfied with the given information about the disease and physical symptom control and education about how the patient needs are to be looked after according to each disease process.

We have looked at whether the Palliative Care Team has looked at difficulties the carer would face ${ }^{13}$ and whether there had been any opportunity to share their views or worries which had been reported as some needs of family. ${ }^{14}$ Assistance in dealing with feeling of inadequacy, guilt anxiety, fear and grief are some other reported needs. ${ }^{14,15}$

The carers were very satisfied about the improvement of quality of life of patients such as finding ways to communicate with patients who had speech difficulties, and alternative methods of feeding to patients who had difficulty in swallowing, difficult symptom control such as pain, help in financial difficulties and for the peaceful death ultimately achieved. Evidence suggests that palliative care consultations are effective in improving the quality of care received by patients and families. Improved assessment and symptom control, met needs, satisfaction with care, comfort in the last two weeks of life, and quality of dying. ${ }^{16}$ In patients who are faced with life limiting illnesses family members are adjusting to the impact of it and its uncertainty. Many are expected to take the complex role of the care giver ${ }^{17}$ and many see this role as their duty. ${ }^{18}$

\section{Strengths and limitations of the study}

Strength of this study is that this is among the very few studies conducted on a Palliative Care Service in Sri Lanka. This is the first instance where a palliative care was established in the country. As the study was conducted in one hospital in Ratnapura the results may not be generalizable to the entirety of Sri Lanka, however the study provides baseline data for future studies.

\section{Implications for clinical practice, teaching and training and research}

This study also highlights the importance of training of health care professionals in providing multidisciplinary palliative care as a team, and to be sensitive to varying 
needs of patients, carers and their families. Establishment of palliative care services at least in Base hospitals and General hospitals, where specialist physicians work would be of importance to Sri Lanka. Some of the difficulties in caring for the patients were in transporting patients, cost incurred and difficulties faced by the carers, such as losing their jobs and sources of income. These gaps can be strengthened through expansion of trained primary care teams in collaboration with other stakeholders, specially to provide more accessible services including home visits. Future research to understand patient, community and health care practitioner beliefs and experiences in palliative care needs will be of value in improving quality of care provided for these patients.

\section{Conclusion}

This study attempts to identify the importance of palliative care services and its impact on caregivers.

\section{Acknowledgements}

The authors would like to thank the National Cancer Control Programme, and nursing officer of the Palliative Care Service and the allied health workers who supported in caring for the patients.

\section{Author contributions}

GUR contributed to the design of the study, managed the study, and drafted the paper. GKP, RK, MCP, LS, CJ J, MAT and SPALR contributed to collection of data, and drafting the paper. REED designed the study, analysed the data and reviewed and edited the paper. All authors read and approved the final manuscript.

\section{References}

1. Saunders C. Social work and palliative care - the early history. Br J Soc Work 2001; 31: 791-9.

2. Thomas K. Out-of-hours palliative care - bridging the gap. Eur J Palliat Care 2000; 7: 22-5.

3. Shipman C, Addington-Hall J, Barclay S, et al. Providing palliative care in primary care: how satisfied are GPs and district nurses with current out-of-hours arrangements? Br J Gen Pract 2000; 50: 477-8.

4. National Institute for Clinical Excellence. Guidance on cancer services: improving supportive and palliative care for adults with cancer - the manual. London: National Institute for Clinical Excellence, 2004.

5. Hunstad I and Foelsvik Svindseth M. Challenges in homebased palliative care in Norway: a qualitative study of spouses' experiences. Int J Palliat Nurs 2011; 17(8): 398-404.

6. Worth A, Boyd K, Kendall M, Heaney D, Macleod U, Cormie P, Murray S. Out-of-hours palliative care: a qualitative study of cancer patients, carers and professionals. $\mathrm{Br} \mathrm{J}$ Gen Pract 2006; 56(522): 6-13.

7. Munday D, Dale J, Barnett M. Out-of-hours palliative care in the UK: perspectives from general practice and specialist services. J R Soc Med 2002; 95: 28-30.

8. Cathy Sampson, Ilora Finlay, Anthony Byrne, Veronica Snow, Annmarie Nelson. The practice of palliative care from the perspective of patients and carers. BMJ Supportive and Palliative Care 2014; 4: 291-8.

9. Perera MC, Tennakoon TMS, Kumarasiri LA, Jayasinghe SMNC, Rathnayake RMWD, Rajapaksha RMAM. Cancer in Sri Lanka: The Question of, "To Tell or Not to Tell". Ceylon Journal of Otolayngology 2013; 3(1): 17-19.

10. Morris SM, King C, Turner M, Payne S. Family carers providing support to a person dying in the home setting: A narrative literature review. Palliative Medicine 2015; 29(6): 487-95.

11. Tuckett A. Qualitative research sampling - the very real complexities. Nurse Researcher 2004; 12(1): 47-61.

12. Finnery Rutton LJ, Arora NK, Akos AD, Rawland J. Information needs and sources of information among cancer patients: A systematic review of research (19802003). Patient Education and Counselling 2005; 57: 250-61.

13. Schofield H, Bloch S, Herrma, H, Murphy B, Nankervis J, Singh B. (Eds.). (1998). Family caregivers: Disability, illness and ageing. Melbourne: Allen and Unwin in association with the Victorian Health Promotion Foundation.

14. Notherhouse L. Impact of cancer on the family. International Journal of Psychiatry in Medicine 1984; 14: 215-42.

15. Hleman JW, Lacery NR, Hassanein RS. Identifying the needs of home caregivers of patients with cancer, Oncology Nursing Forum 1992; 19: 771-7.

16. Casarett D, Pickard A, Bailey FA, Ritchie C, Furman C, Rosenfeld K, Shreve S, Chen Z, Shea JA. Do Palliative Consultations Improve Patient Outcomes? Journal of the American Geriatrics Society, 2008; 56: 593-9.

17. Given BA, Given CW. Family home care for individuals with cancer. Oncology 1994; 8: 77-88.

18. McLaughlin D, Hasson F, Kernohan WG, et al Living and coping with Parkinson's disease: Perception of informal cares. Palliative Medicine 2010; 25(2): 177-82. 